\title{
EL DERECHO A LA VIDA PRIVADA DEL TRABAJADOR Y LOS PODERES DEL EMPLEADOR: JURISPRUDENCIA RECIENTE DEL TRIBUNAL EUROPEO DE DERECHOS HUMANOS ${ }^{1}$
}

\author{
Federico Rosenbaum Carli ${ }^{2}$ \\ Profesor Adjunto de Derecho del Trabajo. Profesor de alta dedicación \\ Universidad Católica del Uruguay
}

\begin{abstract}
En el presente trabajo se analiza la jurisprudencia reciente del Tribunal Europeo de Derecho Humanos en relación con los conflictos generados por la confrontación entre el derecho a la vida privada del trabajador y los poderes del empleador. Asimismo, se orientan definiciones y limitaciones al derecho a la vida privada, aportando además reglas generales, principios y pautas para la resolución de esta clase de conflictos.

This paper analyses the recent rulings of the European Court of Human Rights in relation to the conflicts generated by the confrontation between the right of employees to respect for their private life and the employer's powers. Likewise, definitions and limitations to the right to privacy are provided, considering general rules, principles and guidelines for the resolution of this type of conflict.
\end{abstract}

Title: The right of employees to respect for their private life and the employer's powers: recent rulings of the European Court of Human Rights.

Palabras clave: vida privada, poderes del empleador, derechos inespecíficos, video vigilancia, control del empleador

Keywords: right to private life, employer's powers, non-specific rights, video surveillance, employer control

IUSLabor 2/2020, ISSN 1699-2938, p. 48-73.

DOI. 10.31009/IUSLabor.2020.i02.03

Fecha envío: 26.3.2020 | Fecha aceptación: 27.5.2020

\footnotetext{
1 Las opiniones vertidas en el presente trabajo son a título personal y no comprometen a las organizaciones a las que pertenece o representa el autor.

2 Profesor Adjunto de alta dedicación de Derecho del Trabajo, Universidad Católica del Uruguay. Magíster en Derecho del Trabajo y Relaciones Laborales y Doctorando en Administración, hacienda y justicia en el Estado Social (línea de investigación "El Derecho del Trabajo en el Estado Social de Derecho”), Universidad de Salamanca, España. Correo electrónico: federico.rosenbaum@ucu.edu.uy.
} 


\section{Sumario}

1. Tecnología, vida privada y poderes del empleado

2. Tres casos de la jurisprudencia reciente del TEDH

2.1. El caso BĂRBULESCU vs. RUMANÍA

2.1.1. El fallo de la Cuarta Sección del TEDH

2.1.2. El fallo de la Gran Sala del TEDH

2.2. El caso ANTOVIC y MIRKOVIĆ vs. MONTENEGRO

2.2.1. El fallo de la Segunda Sección del TEDH

2.3. El caso LÓPEZ RIBALDA y OTROS vs. ESPAÑA

2.3.1. El fallo de la Tercera Sección del TEDH

2.3.2. El fallo de la Gran Sala del TEDH

3. Pautas para la resolución de los conflictos entre el derecho a la vida privada y el ejercicio de los poderes del empleador

3.1. El concepto, alcances y límites del derecho a la vida privada del trabajador

3.2. Principios y reglas generales aplicables a los conflictos de esta naturaleza

3.3. Límites a la discrecionalidad de los Estados en la regulación y resolución judicial de esta clase de conflictos

4. Derecho a la vida privada y protección de datos personales

5. Breves apuntes conclusivos

6. Bibliografía 


\section{Tecnología, vida privada y poderes del empleador}

A nivel comparado, en la actualidad es una constante cada vez más creciente encontrar en el desarrollo de las relaciones laborales, conflictos generados por la confrontación entre los poderes empresariales -en concreto, los poderes de dirección, control y disciplinario-, y derechos fundamentales del trabajador -en particular, los inespecíficamente laborales-.

Muchos de esos conflictos se inscriben en el ámbito del uso de las nuevas tecnologías, y en definitiva, se producen por la pugna, por un lado, entre la introducción de novedosos mecanismos de organización empresarial con la finalidad de agilizar los procesos productivos, el control del trabajo y de los dependientes, y por otro lado, los derechos de los trabajadores, en gran medida, al respeto a la vida privada, los datos personales, la inviolabilidad de la correspondencia, entre otros.

Esta confrontación es un fiel reflejo de que nos encontramos en un estadio intermedio, caracterizado por la necesidad de cambios en la estructura empresarial, su organización y las relaciones laborales, derivados -entre otros factores- de la vertiginosidad del avance de las tecnologías y la informática. En definitiva, los avances tecnológicos parecen ser más veloces que la evolución cultural del hombre, que, ante cambios tan profundos, tiende a rechazarlos antes bien que incorporarlos naturalmente y sin resistencias.

De todos modos, claro está que el impacto de las nuevas tecnologías e informática en las relaciones laborales, y su introducción progresiva, deberá adecuarse, y también, adaptarse a fin de no conculcar derechos fundamentales de los trabajadores, y en tal proceso es que se señalan lineamientos básicos por parte de la doctrina y jurisprudencia, así como se van definiendo contenidos y límites en esa pugna entre los poderes empresariales y los derechos inespecíficamente laborales, como el que particularizamos en este trabajo: la vida privada del trabajador.

Uno de los órganos que ha dedicado especial atención a este tipo de situaciones es el Tribunal Europeo de Derechos Humanos -en adelante TEDH-, quien en el marco de la aplicación del Convenio Europeo de Derechos Humanos -en adelante CEDH-, ha debido intervenir para resolver esta clase de conflictos.

El presente trabajo se centra en el análisis de la reciente jurisprudencia del TEDH en relación con la vida privada del trabajador y su confrontación con los poderes empresariales -fundamentalmente limitando nuestro estudio en tres casos de particular 
interés-, y a destacar el valor jurídico de los lineamientos y pautas de solución de esta clase de conflictos que aporta dicho órgano.

\section{Tres casos de la jurisprudencia reciente del TEDH}

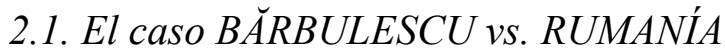

En el caso BĂRBULESCU vs. RUMANÍA ${ }^{3}$, el TEDH resolvió un conflicto en relación con el control empresarial sobre los medios informáticos y la privacidad del trabajador.

En concreto, en relación con los hechos del mismo, cabe destacar que el trabajador había sido despedido en el año 2007, luego de que el empleador constatara que utilizó con fines personales recursos tecnológicos puestos a su disposición. En síntesis, la empresa le había solicitado al trabajador que abriera una cuenta de Yahoo Messenger para responder consultas de clientes -es decir, para un uso estrictamente laboral y profesional-, y en determinado momento de la relación laboral, el empresario detectó que la cuenta fue utilizada para mantener conversaciones personales -entre las cuales se encontraba el hermano y la pareja del trabajador como destinatarios de las mismas-, haciendo efectivo entonces su despido.

El conflicto jurídico surgió con un reclamo judicial a nivel nacional, en el cual el trabajador solicitaba la nulidad de su despido por haberse violentado su derecho fundamental y constitucional a la privacidad de su correspondencia. Los órganos jurisdiccionales de aquel país desestimaron su reclamo, y quedó por ende abierta la vía para acceder a la revisión del caso ante el TEDH.

\subsubsection{El fallo de la Cuarta Sección del TEDH}

Con fecha 12 de enero de 2016, la Cuarta Sección del TEDH entendió por mayoría -6 votos contra 1- que el empleador actuó de acuerdo con su potestad disciplinaria, al acceder a la cuenta de Yahoo Messenger asumiendo que la información contenida en la misma estaba relacionada a la actividad profesional -dado que había prohibido su uso para fines personales-. Por tal motivo, consideró definitivamente que dicho acceso fue legítimo.

Además, agregó que la legitimidad del acceso no se vio alterada por el hecho de que en dicho momento no existían daños actuales para el empleador. En efecto, la Corte entendió que resulta razonable que el empleador quiera verificar el cumplimiento de las tareas profesionales de los trabajadores durante sus horas de trabajo.

\footnotetext{
${ }^{3}$ Caso No 61496/08. Disponible en https://hudoc.echr.coe.int.
} 


\subsubsection{El fallo de la Gran Sala del TEDH}

El 5 de septiembre de 2017, por mayoría de votos -11 contra 6-, la Gran Sala del TEDH consideró que los órganos jurisdiccionales de Rumanía -que intervinieron desestimando el planteo del reclamante-, debieron apelar a un equilibrio entre el interés del empleador -representado por su derecho de vigilancia, control y potestad disciplinaria-, y el interés del trabajador -encarnado por su derecho al respeto a su vida privada y correspondencia-

Como punto de partida, la sentencia reconoció que el empresario tiene un interés legítimo de asegurar el buen funcionamiento de la empresa y que esto puede practicarse estableciendo mecanismos para comprobar que sus trabajadores desempeñan sus obligaciones profesionales adecuadamente y con la diligencia necesaria.

Por otro lado, el TEDH puso de relieve que el juzgador de primera instancia de Rumanía observó que el trabajador no parecía haber sido informado con antelación del alcance y la naturaleza de las actividades de control de su empleador o de la posibilidad de que este tuviera acceso al contenido real de sus comunicaciones.

En función de ello, la sentencia determinó que los tribunales nacionales omitieron considerar si el trabajador había sido previamente notificado de la posibilidad de que el empleador pudiera adoptar medidas de control y del alcance y naturaleza de tales medidas. Asimismo, el TEDH consideró que, para calificarlo como previo aviso, la advertencia del empleador debe verificarse antes de que se inicien las actividades de control, especialmente cuando también implican el acceso al contenido de las comunicaciones de los empleados.

Por otro lado, en referencia al alcance del control y al grado de intrusión en la intimidad del demandante, el TEDH observó que esta cuestión no fue examinada ni por el juzgador de primera instancia, ni por el tribunal de apelación, siendo que había surgido acreditado que el empleador había registrado en tiempo real todas las comunicaciones del trabajador durante el período de supervisión, accedido a ellas e impreso su contenido.

Además, el otro extremo analizado en el fallo se refiere a que los órganos jurisdiccionales nacionales tampoco realizaron una evaluación adecuada de la existencia de motivos legítimos para justificar el control de las comunicaciones del demandante. En efecto, no se había identificado qué propósito específico podía haber justificado un control tan estricto e invasivo en el caso concreto. Asimismo, se destacó que esta cuestión había sido abordada por el juez de primera instancia, que había mencionado la necesidad de evitar que los sistemas informáticos de la empresa resultaran dañados, la 
responsabilidad de la empresa en caso de actividades ilegales en el ciberespacio y los secretos comerciales de la empresa. No obstante lo anterior, a juicio del Tribunal de Justicia estos ejemplos sólo podían considerarse teóricos o hipotéticos, ya que no existía ninguna verificación de que el trabajador hubiera expuesto a la empresa a alguno de dichos riesgos.

Del mismo modo, ni el tribunal de instancia, ni el tribunal de apelación examinaron suficientemente si el objetivo perseguido por el empleador podía haberse logrado mediante métodos menos invasivos que acceder al contenido de las comunicaciones del trabajador, así como tampoco se consideró la gravedad de las consecuencias del control y del procedimiento disciplinario posterior, siendo que el reclamante recibió la sanción disciplinaria más severa, es decir, el despido.

Finalmente, en la decisión del TEDH se señaló que las autoridades nacionales no determinaron en qué momento del procedimiento disciplinario el empleador había accedido al contenido pertinente. Por ello, se concluyó que el hecho de que pueda haberse accedido al contenido de las comunicaciones en cualquier fase del procedimiento disciplinario, resultaba contrario al principio de transparencia.

Consecuentemente, el TEDH consideró que las autoridades nacionales de Rumanía no protegieron adecuadamente el derecho del trabajador al respeto de su vida privada y de su correspondencia, y que, por consiguiente, no adoptaron un justo equilibrio entre los intereses en juego, concluyéndose entonces que existió una violación del artículo 8 de la $\mathrm{CEDH}^{4}$.

\subsection{El caso ANTOVIC y MIRKOVIĆ vS. MONTENEGRO}

En relación con el caso ANTOVIC y MIRKOVIĆ vs. MONTENEGRO 5 , el TEDH intervino resolviendo un conflicto generado entre la introducción de medios de video vigilancia y la vida privada de los trabajadores -tratándose los trabajadores de este caso concreto de docentes universitarios-.

Concretamente, el Decano de la Facultad de Matemáticas de la Universidad de Montenegro, en una sesión del Consejo Escolar, informó a los profesores que

\footnotetext{
${ }^{4}$ El artículo 8 dispone: "1. Toda persona tiene derecho al respeto de su vida privada y familiar, de su domicilio y de su correspondencia. 2. No podrá haber injerencia de la autoridad pública en el ejercicio de este derecho sino en tanto en cuanto esta injerencia esté prevista por la ley y constituya una medida que, en una sociedad democrática, sea necesaria para la seguridad nacional, la seguridad pública, el bienestar económico del país, la defensa del orden y la prevención de las infracciones penales, la protección de la salud o de la moral, o la protección de los derechos y las libertades de los demás".

${ }^{5}$ Caso $\mathrm{N}^{\mathrm{o}}$ 70838/13. Disponible en https://hudoc.echr.coe.int.
} 
allí impartían clases, incluidos los reclamantes, que se había introducido la video vigilancia en los auditorios donde se dictaban las clases.

La decisión formal del Decano especificaba que el objetivo de la medida se dirigía a garantizar la seguridad de los bienes y las personas, incluidos los estudiantes, y la vigilancia de la enseñanza. Asimismo, se estableció que el acceso a los datos que se recopilaban estaba protegido por códigos que solo conocía el Decano, y que estos se almacenaban exclusivamente durante un año.

Posteriormente, los accionantes presentaron un reclamo ante la Agencia de Protección de Datos Personales, sobre la video vigilancia y la recopilación de datos sin su consentimiento -basándose en la Ley de Protección de Datos Personales-. En particular, los solicitantes indicaron que el anfiteatro donde impartían clases estaba cerrado antes y después de las clases, que la única propiedad eran escritorios y sillas fijos y una pizarra, que no conocían ninguna razón para temer por la seguridad de nadie, y que, en cualquier caso, existían otros métodos para proteger a las personas y los bienes y supervisar las clases. En virtud de ello, solicitaron que se quitaran las cámaras y se borrasen los datos almacenados.

Sin perjuicio de ello, la Agencia emitió un informe después de visitar la Facultad de Matemáticas, declarando que la video vigilancia se ajustaba a la Ley de Protección de Datos Personales.

En vista de dicho dictamen, los demandantes presentaron una objeción formal, y finalmente, el Consejo de la Agencia dictó una resolución ordenando a la Facultad de Matemáticas a que retirara las cámaras de los auditorios dentro de quince días, ya que la video vigilancia no estaba de acuerdo con la Ley de Protección de Datos Personales. En particular, el Consejo sostuvo que no se habían acreditado los motivos de la introducción de la video vigilancia, dado que no había pruebas de que existiera un peligro para la seguridad de las personas y los bienes en los auditorios, y menos aún de datos confidenciales. También se indicó que la vigilancia de la enseñanza no se encontraba entre los motivos legítimos de la video vigilancia. A raíz de ello, la Facultad de Matemáticas decidió retirar las cámaras.

Los trabajadores presentaron una demanda de indemnización contra la Universidad de Montenegro, la Agencia de Protección de Datos Personales y el Estado de Montenegro por una violación de su derecho a una vida privada, en particular mediante la recopilación y el tratamiento no autorizados de datos sobre ellos. 
El tribunal de primera instancia de Podgorica se pronunció rechazando la demanda, considerando que la noción de vida privada ciertamente incluía actividades en el ámbito empresarial y profesional, aunque sin embargo, la Universidad era una institución pública que realizaba actividades de interés público, siendo la enseñanza una de ellas, y que, por lo tanto, no era posible que la video vigilancia de los auditorios como lugares públicos violara el derecho de los docentes al respeto de su vida privada. En ese sentido, se describió que se trataba de un área de trabajo, como un tribunal o un parlamento, donde los profesores nunca estaban solos y, por lo tanto, no podían invocar ningún derecho a la privacidad que pudiera violentarse. Asimismo, se concluyó que los datos que se habían recopilado tampoco podían considerarse datos personales. El tribunal sostuvo además que tal conclusión era consistente con la jurisprudencia, dado que el control de las acciones que se llevaban a cabo en público no era una interferencia con la vida privada de una persona cuando esos medios registran lo que otros podrían ver si estuvieran en el mismo lugar al mismo tiempo.

Los recurrentes apelaron, y finalmente el tribunal superior de Podgorica confirmó la sentencia de primera instancia, sustancialmente respaldando sus fundamentos.

En función de ello fue que los trabajadores recurrieron al TEDH, alegando que la instalación y el uso ilegítimo de equipos de video vigilancia en los auditorios universitarios en los que se impartían las clases, habían violado su derecho al respeto de su vida privada, y, por ende, que era contrario al artículo 8 del CEDH.

\subsubsection{El fallo de la Segunda Sección del TEDH}

El TEDH ha sostenido que la video vigilancia encubierta de un empleado en su lugar de trabajo debe considerarse como una intrusión considerable en la vida privada del empleado. Por tal motivo, consideró que constituye una injerencia en el sentido previsto por el artículo 8, y que, por tanto, toda injerencia solo puede justificarse en virtud del artículo 8.2 si se ajusta a la ley, persigue uno más de los objetivos legítimos a los que se refiere dicha disposición y es necesaria en una sociedad democrática, para alcanzar dicho objetivo.

Además, la Corte observó que los tribunales nacionales no examinaron la cuestión de si los actos eran conformes con la ley, dado que no consideraron que la video vigilancia impugnada fuera una intromisión en la vida privada de los demandantes. Sin embargo, la Agencia de Protección de Datos Personales sí lo hizo y, al hacerlo, sostuvo explícitamente que no era conforme a la ley. 
De ese modo, dado que la legislación de Montenegro establece explícitamente que deben cumplirse determinadas condiciones antes de que se recurra a la vigilancia con cámara, y que en el caso en concreto esas condiciones no se cumplieron, y teniendo en cuenta la decisión de la Agencia a este respecto -en ausencia de un examen de la cuestión por parte de los tribunales nacionales-, con fecha 28 de noviembre de 2017, la Corte concluyó por mayoría -4 votos contra 3- que la injerencia en cuestión no se ajustó a la ley, un hecho suficiente para constituir una violación del artículo 8 del CEDH.

\subsection{El caso LÓPEZ RIBALDA y OTROS vs. ESPAÑA}

En cuanto al caso LÓPEZ RIBALDA y OTROS vs. ESPAÑA ${ }^{6}$, el TEDH también resolvió una controversia sobre la introducción de medios de video vigilancia y la vida privada de los trabajadores.

En similar sentido a los casos anteriores, los trabajadores -que se desempeñaban como cajeros de un supermercado- argumentaron que la video vigilancia encubierta ordenada por su empleador sin informarles previamente había violado su derecho a la privacidad protegido por el artículo 8 de la Convención.

La controversia se originó en el momento en que el empleador notó algunas irregularidades y discordancias entre los niveles de stock de los supermercados y lo que realmente se vendía a diario -generándose pérdidas económicas importantes en los mismos-.

Para investigar y poner fin a las pérdidas económicas, el empleador decidió instalar cámaras de vigilancia que consistían en cámaras visibles y ocultas. El propósito de las cámaras visibles era registrar posibles robos de clientes y apuntar hacia las entradas y salidas del supermercado. El propósito de las cámaras ocultas era registrar y controlar los posibles robos de empleados, que enfocaban a los mostradores de pago y el área detrás de la caja. La empresa avisó a sus trabajadores de la instalación de las cámaras visibles, aunque ni ellos ni el comité de empresa fueron informados de las cámaras ocultas.

En definitiva, los trabajadores fueron despedidos por motivos disciplinarios, ya que se constató en un video que ayudaron a compañeros de trabajo y clientes a robar artículos, así como a robarlos ellos mismos. Según sus cartas de despido, las cámaras de seguridad los habían identificado escaneando artículos de las cestas de comestibles de los clientes y compañeros de trabajo, y luego cancelando las compras. También se había

\footnotetext{
${ }^{6}$ Casos No $1874 / 13$ y 8567/13. Disponible en https://hudoc.echr.coe.int.
} 
identificado que los clientes y compañeros de trabajo salían de la tienda con mercancías que no habían sido abonadas.

Los trabajadores recurrieron dicho despido ante los tribunales españoles, argumentando que mediante el uso de la video vigilancia encubierta se había violado su derecho a la protección de su privacidad. Sin embargo, dicha petición fue rechazada en todas las instancias judiciales por razones sustanciales y/o procesales -Juzgado de lo Social, Tribunal Superior de Justicia, Tribunal Supremo y Tribunal Constitucional-, declarando que los despidos eran justificados.

La justicia de primera y segunda instancia se fundó en jurisprudencia anterior del Tribunal Constitucional, señalando que en los casos en que existen sospechas de robo, circunstancias especiales justifican la interferencia con el derecho a la privacidad de un empleado, considerándose apropiado para el objetivo legítimo perseguido, necesario y proporcionado.

Sin perjuicio de ello, se reconoció que era posible que el empleador pudiera enfrentar una sanción administrativa por no informar a sus empleados y al comité de empresa de la instalación de las cámaras, aunque ese hecho por sí solo no fue considerado relevante desde el punto de vista constitucional, ya que desde esa perspectiva, la video vigilancia encubierta había sido justificada -en la medida en que había habido sospechas razonables de robo-, apropiada para el objetivo legítimo perseguido, necesaria y proporcionada.

\subsubsection{El fallo de la Tercera Sección del TEDH}

El día 9 de enero de 2018, la Tercera Sección del TEDH dictó sentencia examinando si el Estado, en el contexto de sus obligaciones positivas en virtud del artículo 8, había logrado un equilibrio justo entre el derecho de los demandantes al respeto de su vida privada y el interés de su empleador en la protección de su organización y los derechos de gestión relativos a sus derechos de propiedad, así como el interés público en la adecuada administración de justicia.

En función de ello, determinó que la video vigilancia encubierta se llevó a cabo después de que el supervisor de la tienda había detectado pérdidas, lo que planteaba una sospecha discutible de robo cometido por los accionantes, así como otros empleados y clientes.

Asimismo, la Corte destacó que los datos visuales obtenidos implicaron el almacenamiento y procesamiento de datos personales, estrechamente relacionados con 
la esfera privada de las personas. En efecto, varias personas que trabajaban para el empleador -entre otras, el representante sindical y el representante legal de la empresaprocesaron y examinaron este material antes de que se informara a los reclamantes de la existencia de las grabaciones de video.

Del mismo modo, según reconocieron los tribunales españoles, el empleador incumplió con la obligación de informar a los interesados sobre la existencia de un medio para recopilar y procesar sus datos personales, según lo prescrito en la legislación nacional. A pesar de ello, los tribunales nacionales consideraron que la medida había sido justificada -dado que había sospechas razonables de robo-, apropiada para el objetivo legítimo perseguido, necesaria y proporcionada, ya que no había ningún otro medio igualmente efectivo para proteger los derechos del empleador, lo que habría interferido menos con el derecho de los reclamantes a respetar su vida privada.

En definitiva, el TEDH no compartió la opinión de los tribunales nacionales sobre la proporcionalidad de las medidas adoptadas por el empleador con el objetivo legítimo de proteger el interés del mismo en la protección de sus derechos de propiedad. De ese modo, enfatizó en que la video vigilancia llevada a cabo por el empleador, que tuvo lugar durante un período prolongado, no cumplió con los requisitos estipulados en la legislación española, en particular, con la obligación de haber informado de forma previa y explícitamente, de manera precisa e inequívoca a los interesados sobre la existencia y las características particulares de un sistema que recopila datos personales.

Por ello es que la Corte observó que los derechos del empleador podrían haberse salvaguardado por otros medios, al menos en cierta medida, en particular informando previamente a los solicitantes, incluso de manera general, sobre la instalación de un sistema de video vigilancia y proporcionarles la información prescrita en la legislación española.

Del examen anterior, y sin perjuicio del margen de apreciación del Estado español, el TEDH concluyó por mayoría -6 votos contra 1-, que los tribunales nacionales no lograron establecer un equilibrio justo entre el derecho de los trabajadores al respeto de su vida privada en virtud del artículo 8 de la Convención y el interés de su empleador en la protección de su derecho de propiedad.

\subsubsection{El fallo de la Gran Sala del TEDH}

La intervención de la Gran Sala del TEDH fue particularmente trascendente, dado que con fecha 17 de octubre de 2019, dictó sentencia definitiva por decisión mayoritaria -14 votos contra 3-, rechazando el reclamo de los trabajadores. 
En sustancia, señaló que la existencia de una expectativa razonable de protección y respeto a la privacidad de los trabajadores estaba necesariamente limitada. Ello por cuanto su lugar de trabajo -un supermercado-, estaba abierto al público y que las actividades filmadas allí, a saber, la toma de pagos por compras clientes, no eran de naturaleza íntima o privada. Sin embargo, destacó que incluso en lugares públicos la introducción de una grabación sistemática o permanente de imágenes de personas y su procesamiento posterior podría plantear preguntas que afectan la vida privada de las personas involucradas.

Por este motivo, destacó que los trabajadores habían sido informados sobre la instalación de unas cámaras en el supermercado, siendo visibles y posicionadas para filmar las entradas y salidas de la tienda. En esas circunstancias, el TEDH indicó que los trabajadores tenían una expectativa razonable de que no serían sometidos a video vigilancia en otras áreas de la tienda sin ser informados con antelación.

Como punto de partida conceptual, el fallo consideró que el requisito de transparencia y el correlativo derecho a la información son de naturaleza fundamental, particularmente en el contexto de las relaciones laborales, donde el empleador tiene asignados poderes significativos con respecto a los empleados y se debe evitar cualquier abuso en el ejercicio de dichos poderes. Sin embargo, la Corte señaló que la provisión de información al individuo que se está monitoreando y su alcance constituyen sólo uno de los criterios a tener en cuenta para evaluar la proporcionalidad de una medida de este tipo. Sin embargo, en ausencia de dicha información, las salvaguardas derivadas de los otros criterios deben ser aún más importantes.

Dada la importancia del derecho a la información en tales casos, el Tribunal entendió que solo un requisito primordial relacionado con la protección de intereses públicos o privados significativos podría justificar la falta de información previa.

En ese contexto, el TEDH entendió que los tribunales españoles consideraron correctamente que la interferencia con la privacidad de los trabajadores fue proporcional.

A pesar de ello, expresamente señaló que no sería posible aceptar la premisa general de que la más mínima sospecha de apropiación indebida o cualquier otro delito por parte de los trabajadores podría justificar la instalación de cámaras de video vigilancia encubiertas por parte del empleador.

La existencia de sospechas razonables de que se ha cometido una falta grave y el alcance de las pérdidas identificadas en el presente caso constituyeron una justificación 
importante. Esto constituye un elemento aún más significativo en una situación en la que el buen funcionamiento de una empresa se ve amenazado no solo por la sospecha de mal comportamiento de un solo empleado, sino más bien por la sospecha de una acción concertada por parte de varios empleados, ya que esto crea una atmósfera general de desconfianza en el lugar de trabajo.

\section{Pautas para la resolución de los conflictos entre el derecho a la vida privada y el ejercicio de los poderes del empleador}

De la lectura de los fallos comentados, así como de otros dictados por el TEDH, es posible extraer varias pautas e indicadores de solución a los conflictos generados entre el derecho fundamental a la vida privada del trabajador, y los poderes de control, dirección y disciplinario del empresario.

Además, los lineamientos jurídicos aportados por este Tribunal son muy importantes e influyentes en la actualidad, dado que el desarrollo de las tecnologías y su paulatina introducción como mecanismos de control y organización del trabajo en el ámbito de la empresa, constituye una fuente de conflicto con el derecho fundamental al respeto a la vida privada.

El primero de estos lineamientos se refiere al concepto, alcance y límites del derecho a la vida privada del trabajador. El segundo aspecto se relaciona con ciertos principios y reglas generales aplicables a los conflictos de esta naturaleza; y finalmente, la consideración de la existencia de límites a la discrecionalidad de los Estados en la regulación y resolución judicial de estos conflictos.

Estos dos últimos aspectos han sido considerados especialmente para el caso del control de las comunicaciones o correspondencia. De todos modos, resulta lógico señalar que dichos principios y límites son extensibles en gran medida, por ejemplo, a la video vigilancia o grabaciones de sonido en el ámbito del trabajo, o cualquier medio de vigilancia electrónica o informática ${ }^{7}$.

\subsection{El concepto, alcance y límites del derecho a la vida privada del trabajador}

Como punto de partida, en cada caso sometido a su resolución la Corte europea analiza si ha existido violación del artículo $8 \mathrm{del} \mathrm{CEDH}$, que dispone que toda persona tiene

\footnotetext{
${ }^{7}$ GaLlardo, Rosa, "Un límite a los límites de la vida privada y de la correspondencia en los lugares de trabajo. Comentario a la sentencia del Tribunal Europeo de Derechos Humanos (Gran Sala) de 5 de setiembre de 2017 en el caso Barbulescu II c. Rumania", Revista de Derecho Social, No 79, Editorial Bomarzo, Albacete, 2017, p. 147.
} 
"derecho al respeto de su vida privada y familiar, de su domicilio y de su correspondencia".

Por este motivo, si se pretende resolver adecuadamente esta clase de conflictos, se torna imperioso un análisis desde la consideración del derecho a la vida privada del trabajador como un derecho humano fundamental. En virtud de ello, dentro de dicho marco jurídico, se ha señalado que "la titularidad y goce de tales derechos (universales, irrenunciables e indisponibles), mal podrían verse afectados por la celebración de un contrato de trabajo... Como alguna vez bien dijo Romagnoli, al ingresar a la fábrica, el trabajador no deja colgados en la reja, junto a su gorra, los derechos humanos de que es titular, ni los guarda en el ropero del vestuario, junto a su abrigo, para retomarlos al fin de la jornada"8. En definitiva, se han identificado a estos derechos inespecíficamente laborales -dentro de los cuales se ubica a la vida privada del trabajador-, como los "derechos del ciudadano-trabajador, que ejerce como trabajadorciudadano"9.

En ese contexto, el TEDH ha ido construyendo una jurisprudencia uniforme -no sin resistencias o disidencias entre los propios magistrados- en relación con los conflictos entre el control empresarial sobre los medios informáticos y la privacidad del trabajador, y paulatinamente ha definido de manera cada vez más extensiva el concepto de "vida privada" del trabajador, para englobar situaciones como la "vida social privada", y zonas de interacción de una persona con otras, incluso en un contexto público.

En ese sentido, la Corte ha referido a que "vida privada" es un término amplio no susceptible de definición exhaustiva y que sería demasiado restrictivo limitar la noción a un "círculo interno" en el que el individuo puede vivir su propia vida personal como él elige y excluir de ella completamente el mundo exterior ${ }^{10}$. De ese modo, se entiende que el artículo 8 referido, garantiza el derecho a la "vida privada" en sentido amplio, incluido el derecho a llevar una "vida social privada", es decir, la posibilidad de que el

\footnotetext{
${ }^{8}$ ERMIDA URIARTE, Óscar, "Derechos humanos laborales en el derecho positivo uruguayo", en BARRETO GHIONE, HUGO, Investigación sobre la aplicación de los principios y derechos fundamentales en el trabajo en Uruguay, Organización Internacional del Trabajo, Lima, 2006, p. 14.

${ }^{9}$ Palomeque López, Manuel Carlos y Álvarez De La Rosa, Manuel, Derecho del Trabajo, Editorial Universitaria Ramón Areces, vigesimocuarta edición, Madrid, p. 104.

10 Ello ha llevado a que se refiriera a este derecho como un "concepto jurídico indeterminado" (Chacartegui, Consuelo; "Videovigilancia en el lugar de trabajo y "expectativa razonable de privacidad' según el Tribunal Europeo de Derechos Humanos. Comentario a la sentencia de 9 de enero de 2018 [caso López Ribalda contra España]", Revista de Derecho Social, № 83, Editorial Bomarzo, Albacete, 2018, p. 121).
} 
individuo desarrolle su identidad social. En ese sentido, el derecho en cuestión consagra la posibilidad de acercarse a otros para establecer y desarrollar relaciones con ellos.

El concepto de vida privada también se extiende a aspectos relacionados con la identidad personal, como el nombre o la imagen de una persona. En ese sentido, la imagen de una persona constituye uno de los principales atributos de su personalidad, ya que revela características únicas y la distingue de los demás. El derecho a la protección de la imagen de uno es, por lo tanto, uno de los componentes esenciales del desarrollo personal y presupone el derecho a controlar el uso de esa imagen.

Adicionalmente, la Corte ha sostenido que la noción de "vida privada" puede incluir actividades profesionales o actividades que tienen lugar en un contexto público. Por lo tanto, se ha señalado que existe una zona de interacción de una persona con otras, incluso en un contexto público, que puede estar dentro del alcance de la "vida privada".

A fin de determinar el alcance de la noción de "vida privada", en varias ocasiones el TEDH ha desentrañado si las personas tenían una expectativa razonable de que se respetaría y protegería su privacidad -expectativa razonable de confidencialidad-. En ese contexto, ha declarado que una expectativa razonable de privacidad es un factor significativo, aunque no necesariamente concluyente.

Asimismo, se ha señalado que en determinadas actividades en concreto existe una expectativa legítima y razonable de privacidad. Así, por ejemplo, el TEDH sostiene que en un ambiente académico donde tanto la enseñanza como las actividades de aprendizaje están cubiertas por la libertad académica, dicha expectativa de privacidad puede considerarse "razonable". Por ello, en ese contexto, la vigilancia como medida de control no es algo que un docente normalmente debería esperar -caso ANTOVIC y MIRKOVIĆ vs. MONTENEGRO-.

\subsection{Principios y reglas generales aplicables a los conflictos de esta naturaleza}

El TEDH ha destacado una serie de reglas, principios o consideraciones generales aplicables a los conflictos de esta naturaleza, considerando que:

1. El Derecho del Trabajo posee características específicas que deben tenerse en cuenta, como, por ejemplo, que se rige por sus propias normas jurídicas, que difieren considerablemente de las aplicables en general a las relaciones entre particulares. 
2. Pocos Estados miembros han regulado en forma expresa la cuestión del ejercicio por los trabajadores de su derecho al respeto de su vida privada y de su correspondencia en el lugar de trabajo.

3. La elección de los medios para garantizar el cumplimiento del artículo 8 en el ámbito de las relaciones entre individuos es, en principio, un asunto que cae dentro del margen de apreciación de los Estados. Al mismo tiempo, existen diferentes formas de garantizar el respeto a la vida privada, y la naturaleza de la obligación del Estado dependerá del aspecto particular de la vida privada en cuestión.

4. Debe concederse a los Estados un amplio margen de apreciación al evaluar la necesidad de establecer un marco jurídico que regule las condiciones en las que un empresario puede regular las comunicaciones electrónicas u otras comunicaciones de carácter no profesional por parte de sus empleados en el lugar de trabajo. Sin embargo, el TEDH subraya que la discreción de que gozan los Estados en este campo no puede ser ilimitada.

5. En definitiva, aunque el propósito del artículo 8 sea esencialmente proteger al individuo contra la injerencia arbitraria de las autoridades públicas, no solo obliga al Estado a abstenerse de tal injerencia; sino que además de este compromiso principalmente negativo, pueden existir obligaciones positivas inherentes a un respeto efectivo por la vida privada. Estas obligaciones pueden implicar la adopción de medidas diseñadas para asegurar el respeto de la vida privada incluso en el ámbito de las relaciones de los individuos entre sí ${ }^{11}$

6. En cada caso, el TEDH debe examinar si el Estado, en el contexto de sus obligaciones positivas en virtud del artículo 8, logra un equilibrio justo entre el derecho de los trabajadores al respeto de su vida privada, y el interés de su empleador en la protección de su propiedad, organización y poderes de dirección y control, así como el interés público en la adecuada administración de justicia.

\footnotetext{
${ }^{11}$ En ese sentido, se ha identificado a esta concepción como un mecanismo o vía de ampliación de la protección de los derechos sociales, al que se la denomina como "la teoría de las obligaciones positivas a cargo de los Estados Parte en el Convenio" (TERRADILlos, Edurne "El principio de proporcionalidad como referencia garantista de los derechos de los trabajadores en las últimas sentencias del TEDH dictadas en materia de ciberderechos: un contraste con la doctrina del Tribunal Constitucional Español", Revista de Derecho Social, № 80, Editorial Bomarzo, Albacete, 2017, p. 140).

Asimismo, mediante las obligaciones positivas se ha conseguido "una suerte de eficacia horizontal directa de su jurisprudencia, que afecta de modo claro a las relaciones entre privados" (CABEZA, Jaime "La protección jurisdiccional de los derechos humanos y libertades fundamentales de los trabajadores ante el TEDH", Revista de Derecho Social, N 69, Editorial Bomarzo, Albacete, 2015, p. 101).
} 


\subsection{Límites a la discrecionalidad de los Estados en la regulación y resolución judicial de esta clase de conflictos}

En virtud de lo anterior, la propia Corte europea ha concretado ciertos límites a la discrecionalidad de los Estados en la regulación y resolución judicial de esta clase de conflictos. En virtud de ello, el TEDH plantea que:

1. Las autoridades nacionales deben procurar que la introducción de medidas de control por parte del empleador, independientemente de la extensión y la duración de las mismas, vaya acompañada de garantías adecuadas y suficientes contra todo posible abuso.

2. Dentro de esas garantías, constituyen elementos esenciales la proporcionalidad y ciertas tutelas y previsiones de carácter procesal. En ese contexto, se ha destacado que resulta esencial considerar los siguientes extremos:

a. Si el trabajador ha sido notificado sobre la posibilidad de que el empleador pueda tomar medidas para vigilar y la aplicación de tales medidas. Si bien en la práctica los trabajadores pueden ser notificados de diversas maneras en función de las circunstancias fácticas particulares de cada caso, la Corte considera que para que las medidas sean compatibles con los requisitos del artículo 8 de la Convención, la notificación debe ser clara en cuanto a la naturaleza de la vigilancia y ser previa a la adopción de las mismas.

Además, sobre este punto la doctrina coincide en que dicha información ha de ser previa, catalogándose como un deber o principio de transparencia, que forma parte del derecho a la protección de datos personales ${ }^{12}$, del contenido esencial del derecho al secreto de las comunicaciones ${ }^{13}$, y en general de los derechos relativos a la privacidad del trabajador ${ }^{14}$.

Ello había llevado a que la Tercera Sección del TEDH entendiera que el incumplimiento de este requisito por parte del empleador conllevara necesariamente a la declaración de una vulneración del derecho fundamental del trabajador. En definitiva, bajo esa interpretación se postulaba que el juzgador debía analizar primeramente si se había cumplido con este principio de transparencia. En caso negativo, se debería determinar que el derecho fundamental fue vulnerado; y en caso positivo, se podría continuar con el

\footnotetext{
${ }^{12}$ Chacartegui, Consuelo Ob. cit., p. 122 y ss.

${ }^{13}$ Terradillos, Edurne, Ob. cit., p. 146.

14 Ídem., p. 162.
} 
análisis del test de proporcionalidad de la medida adoptada por el empleador -o 'test Barbulescu', tal como ha sido denominado por PRECIADO DOMÈNECH $^{15}$-, y con los restantes indicadores que reseñaremos seguidamente y que enuncia el TEDH.

En ese contexto existieron posturas interpretativas que rechazaron las conclusiones del TEDH, sobre la base de entender que "el debido respeto a los derechos fundamentales de los trabajadores no puede servir de asidero para mitigar o dejar sin efecto conductas ciertamente irregulares y reprochables por parte de éstos" ${ }^{16}$. En cambio, contrariamente a dicha observación, otra parte de la doctrina científica se había decantado por señalar que "el deber de información sobre la existencia de un sistema de videovigilancia requiere no solo la colocación de carteles informativos genéricos de su instalación, sino que también ha de comunicarse su finalidad y, por tanto, la posibilidad de su utilización para controlar y sancionar a los trabajadores" "17; así como también se indicó que el TEDH parecía inclinarse por pretender excluir con carácter general la introducción de medios de videovigilancia encubiertos ${ }^{18}$. Incluso, partiendo de la base de la jurisprudencia del TEDH dictada hasta el momento del fallo de la Tercera Sección comentado, en el caso español se había planteado la necesidad de que la doctrina de la STC 39/2016 se corrigiera de forma inmediata $^{19}$.

Sin embargo, luego la Gran Sala -caso LÓPEZ RIBALDA y otros vs. ESPAÑAha borrado con el codo lo que escribió previamente con la mano la Tercera Sección. En efecto, le restó importancia a este elemento, al entender que la

\footnotetext{
${ }^{15}$ Preciado Domènech, Carlos, "Comentario de urgencia a la STEDH de 05 de septiembre de 2017. Caso Barbulescu contra Rumanía [Gran Sala]. Recuperando la dignidad en el trabajo", Jurisdicción Social. Blog de la Comisión de lo Social de Juezas y Jueces para la Democracia, 5.09.2017. Disponible en https://bit.ly/2zeEMai.

16 TALÉNS, Eduardo "Vídeo-vigilancia y protección de datos en el ámbito laboral: una sucesión de desencuentros", Revista Internacional y Comparada de Relaciones Laborales y Derecho del Empleo, Volumen 6, No 3, ADAPT, julio-septiembre, 2018, p. 81.

${ }^{17}$ ECHEVERRIA DE RADA, María Teresa, "Protección de datos y Videovigilancia en el ámbito laboral", Actualidad Civil, No 9, Wolters Kluwer, septiembre, 2019. Disponible en https://laleydigital-laleynext-es, LALEY 10667/2019, p. 18 [consultado el día 12.06.2020].

18 García Murcia, Joaquín; Rodríguez CARDo, Iván y Álvarez Alonso, Diego., "Poderes empresariales y derechos del trabajador en el contexto de las nuevas tecnologías: aportaciones recientes de la legislación española", Minerva: Revista de Estudos Laborais, Año IX, I de $4^{\mathrm{a}}$ Serie, No 2, 2019, p. 222.

${ }^{19}$ CABEZA, Joaquín, "El necesario cambio en la jurisprudencia constitucional sobre videovigilancia y control de mensajería electrónica de los trabajadores a la vista de la doctrina del TEDH", Temas Laborales, $\mathrm{N}^{\mathrm{o}} 141 / 2018,2018$, p. 36.
} 
provisión de información al individuo que se está monitoreando, y la determinación de su alcance, constituyen solo uno de los criterios a tener en cuenta para evaluar la proporcionalidad de una medida de este tipo.

Es por ello que podría señalarse que el TEDH desdibuja el vértice de la pirámide del análisis, al incluir al derecho de información previa dentro del test de proporcionalidad, como un elemento más que debiera ser incorporado a la consideración global de cada caso, en lugar de tener por sí solo la virtualidad de operar como un límite a los poderes empresariales.

Ello nos obliga entonces a formular la siguiente pregunta crítica: ¿el derecho de información previa no constituye uno de los contenidos esenciales del derecho a la vida privada del trabajador?

Parte de la doctrina científica ya se ha encargado de matizar las consecuencias del referido fallo, al manifestar que "no se alteran las líneas generales de la jurisprudencia del TEDH sobre la protección y aplicación del artículo 8 del $C E D H$, aun cuando ciertamente se amplía la posibilidad de la adopción de medidas por parte empresarial para poder controlar, en determinadas circunstancias, la prestación laboral de una o más personas trabajadoras sobre las que se tenga sospechas fundadas, no meros indicios, de una actuación contraria a derecho y que pueda tener repercusiones negativas para las personas trabajadoras afectadas no solo en el ámbito laboral sino también en el penal" 20 .

b. El grado de control por parte del empleador y el grado de intrusión en la privacidad del empleado. Sobre este punto, debe efectuarse una distinción entre el control del flujo de comunicaciones y su contenido. También ha de tenerse en cuenta si se han supervisado todas las comunicaciones o sólo una parte de ellas, así como la cuestión de si el seguimiento era limitado en el tiempo y el número de personas que tuvieron acceso a los resultados. Lo mismo se aplica a los límites espaciales de la vigilancia.

\footnotetext{
${ }^{20}$ ROJO TORRECILLA, Eduardo, "Medias verdades y fake news en el mundo jurídico. No cabe todo en la videovigilancia de una persona trabajadora. A propósito de la sentencia "López Ribalda" de la Gran Sala del TEDH de 17 de octubre de 2019 (y recordatorio de la sentencia de Sala de 9 de enero de 2018 y del caso Barbulescu II, sentencia de Gran Sala de 5 de septiembre de 2017)", El nuevo y cambiante mundo del trabajo. Una mirada abierta y crítica a las nuevas realidades laborales, entrada de Blog del 23.10.2019. Disponible en http://www.eduardorojotorrecilla.es/2019/10/medias-verdades-y-fake-newsen-el-mundo.html [consultado el día 13 de junio de 2020].
} 
c. Si el empleador ha aportado razones legítimas para justificar el control de las comunicaciones y el acceso a su contenido. Dado que la vigilancia del contenido de las comunicaciones es por naturaleza un método claramente más invasivo, requiere una justificación más importante.

d. Si hubiera sido posible establecer un sistema de control basado en métodos y medidas menos invasivos que el acceso directo al contenido de las comunicaciones del empleado. En función de este criterio, procede evaluar, teniendo en cuenta las circunstancias particulares de cada caso, si el objetivo perseguido por el empresario podría haber sido alcanzado sin acceder directamente al contenido íntegro de las comunicaciones del empleado.

e. Las consecuencias de la vigilancia para el trabajador sujeto a ella; asimismo, la utilización por el empresario de los resultados de la operación de control, en particular si los resultados se utilizaron para alcanzar la finalidad declarada de la medida.

f. Si el trabajador recibió garantías adecuadas, especialmente cuando las operaciones de control del empleador son de carácter intrusivo. Dichas salvaguardias deberían garantizar, en particular, que el empresario no pueda acceder al contenido de las comunicaciones de que se trate, a menos que el trabajador haya sido previamente informado de dicha eventualidad.

g. Las autoridades nacionales deberían velar por que un empleado cuyas comunicaciones hayan sido objeto de control, tenga acceso a un recurso ante un órgano judicial, para determinar al menos en sustancia, cómo se observaron los criterios antes mencionados y si las medidas impugnadas eran legítimas o no.

\section{Derecho a la vida privada y protección de datos personales}

En otro orden, es preciso señalar que algunos ordenamientos jurídicos han reconocido que los derechos a la vida privada y a la protección de datos personales, poseen autonomía propia, jerarquizándose e independizándose entre sí. En efecto, aún cuando ambos se encuentren íntimamente relacionados, constituyen derechos fundamentales diferentes en su esencia.

A vía de ejemplo, el Tribunal Constitucional español introdujo una diferenciación entre ambos derechos fundamentales, reconociendo que tienen el mismo objetivo de proteger eficazmente la vida personal y familiar privada del individuo, aunque destacando que la 
diferencia principal deriva de la función, objeto y contenido de esos derechos ${ }^{21}$. En ese mismo sentido, la propia Carta de los Derechos Fundamentales de la Unión Europea así los ha distinguido respectivamente en sus artículos 7 ("Respeto a la vida privada y familiar") y 8 ("Protección de datos de carácter personal”).

En efecto, se ha indicado que "[d]e la defensa del núcleo básico de la intimidad entendida como pretensión de no injerencia de terceros, se ha evolucionado hacia una nueva dimensión existencial de la persona, que supone reconocer un derecho de autodeterminación informativa, que faculta a la persona a mantener el poder de disposición sobre el patrimonio informativo" ${ }^{22}$.

Asimismo, se ha descripto y catalogado al derecho a la intimidad como un "derecho negativo de inmunidad o de exclusión" 23 , en tanto considerados como de "libertad contra", o de "posibilidad de defenderse", en oposición a aquellos considerados como de "libertad de" 24 , o que adquieren una dimensión activa -como lo son la libertad de expresión e información, la objeción de conciencia, libertad religiosa, entre otros-.

Tal clasificación se deriva de la propia función del derecho a la intimidad, que se circunscribe a la necesidad de proteger frente a invasiones que puedan realizarse en el ámbito de la vida personal y familiar que una persona desee excluir del conocimiento de los demás, así como de las intromisiones contra su voluntad.

A los efectos de cumplir con esa función, se identifica como un atributo del derecho a la intimidad a la facultad de abstención de injerencias por parte de terceros, extensible tanto al acceso en forma ilegítima a datos de la esfera íntima de la persona, así como a la revelación, divulgación o utilización sin autorización de su titular ${ }^{25}$. Este atributo del derecho a la intimidad ha sido considerado por la doctrina como el núcleo central del derecho fundamental ${ }^{26}$.

\footnotetext{
${ }^{21}$ Tribunal Constitucional español, Pleno, Sentencia No. 292/2000 de fecha 30 de noviembre de 2000, Recurso de inconstitucionalidad No. 1.463/2000.

${ }^{22}$ GOÑI, José Luis, "Los derechos fundamentales inespecíficos en la relación laboral individual: ¿necesidad de una reformulación?", Los derechos fundamentales inespecíficos en la relación laboral y en materia de protección social, Ediciones Cinca, Madrid, 2014, p. 40.

${ }^{23}$ GOÑI, José Luis, Ob. cit., p. 38.

${ }^{24}$ Ídem, pág. 30.

${ }^{25}$ TORTUERo PlazA, José Luis., "La información relativa a la salud y el derecho a la intimidad en la doctrina del TC", La jurisprudencia constitucional en materia laboral y social en el período 1999-2010, Libro Homenaje a María Emilia Casas, La Ley, 2015, p. 342.

${ }^{26}$ PALOMEQUE LóPEZ, Manuel Carlos y ÁLVAREZ DE LA ROSA, Manuel, Ob. cit., p. 116.
} 
Por otro lado, la protección de los datos personales no se reduce solamente a los datos íntimos, sino a cualquier dato de carácter personal, cuyo conocimiento por terceros puede afectar los derechos de la persona.

Además, la función del derecho a la protección de datos personales es la de garantizar a la persona de un poder relativo al control de sus datos, el uso y destino de los mismos, con la finalidad de impedir su tráfico ilícito, susceptible de ocasionar una lesión para la dignidad de su titular.

Por ello, se suele coincidir en afirmar que el derecho a la protección de datos personales atribuye a su titular un derecho a que se requiera el previo consentimiento para la recogida y uso de los datos personales; un derecho a conocer y ser informado sobre el uso y destino de esos datos; y un derecho a acceder, rectificar y cancelar los datos ${ }^{27}$.

En definitiva, el amparo del derecho a la intimidad o vida privada se ve complementado por la protección de los datos personales, y por ello, los conflictos generados en las relaciones laborales -tales como los analizados en este trabajo-, se complejizan, al exigírsele al empleador el cumplimiento con el deber de información previa, "como especial medio de protección de la autodeterminación informativa" 28 .

Sin perjuicio de dicha palmaria diferenciación, que naturalmente se refleja en el tratamiento idependizado que aportan tanto la doctrina científica como la jurisprudencia nacional de cada país, corresponde puntualizar que el CEDH no ha optado por particularizar ambos derechos fundamentales a la vida privada y protección de datos personales, sino que, por el contrario, ha condensado una protección genérica del respeto a la vida privada y familiar por intermedio del ya citado artículo 8. Es por este motivo que el fundamento normativo de las sentencias comentadas en el presente trabajo se ha concentrado en esa previsión y sin ponderar las diferencias entre estos derechos que algunos sistemas jurídicos consignan a nivel interno.

Como corolario de lo anterior, en las sentencias del TEDH se evidencia un análisis global de los contenidos de ambos derechos en cada caso sometido a su resolución, aunque sin particularizarlos o autonomizarlos. Así es que se destacan dos etapas en el proceso de verificación del cumplimiento del artículo 8 del $\mathrm{CEDH}$; una primera, centrada en la comprobación previa del cumplimiento con el deber de información -

\footnotetext{
${ }^{27}$ Tribunal Constitucional español, Pleno, Sentencia No. 38/2016 de fecha 3 de marzo de 2016, Recurso de amparo $\mathrm{n}^{\circ} 722 / 2013$.

${ }^{28}$ HenRíQUez, Sebastián, "Protección de datos, videovigilancia laboral y doctrina de la sentencia López Ribalda II: un peligroso camino hacia la degradación de la obligación de información”, IUSLabor, 3/2019, 2019, p. 59.
} 
inherente al núcleo esencial del derecho a la protección de datos personales-; y una segunda, aplicando una ponderación reglada por el principio de proporcionalidad donde allí entrará al análisis la posible vulneración del derecho a la intimidad o vida privada, o incluso alguna otra faceta de la protección de datos personales- ${ }^{29}$.

\section{Breves apuntes conclusivos}

Los avances tecnológicos tienen la virtualidad de proyectar mayores riesgos de intromisiones en la esfera íntima o privada de los trabajadores ${ }^{30}$, y en los hechos, tal extremo se ha visto reflejado en los diversos conflictos que se generan en el marco de la introducción de tecnologías por parte del empleador, con el fin, entre otros, de monitorear el cumplimiento de las obligaciones laborales. La jurisprudencia comentada del TEDH resulta de fundamental interés en el marco del futuro del trabajo, la era digital, las tecnologías de la información y comunicación, y el big data.

Asimismo, es indudable que no les corresponde a los operadores jurídicos aislarse a la hora de encontrar soluciones concretas a los problemas generados por la confrontación de los derechos fundamentales del trabajador, inespecíficamente laborales, con los poderes de dirección, de control y disciplinario del empresario, máxime teniendo presente de que se trata de una realidad compartida por todos los individuos y Estados.

En efecto, la introducción de nuevas tecnologías -y no tan nuevas- en la estructura de organización empresarial, y como mecanismo de control de la prestación laboral, es una constante reflejada a nivel mundial. En ese marco común, también se proyecta una dificultad compartida de "encontrar el punto óptimo de equilibrio entre los diversos intereses concurrentes" $" 31$.

También cabe destacar que además de la regulación normativa europea que se analiza en estos fallos, el derecho a la protección de la vida privada ante injerencias arbitrarias o abusivas es recogido por otros instrumentos internacionales, como la Declaración Universal de los Derechos Humanos (artículo 12), el Pacto Internacional de Derechos Civiles y Políticos (artículo 17), la Convención Americana sobre Derechos Humanos, Pacto San José de Costa Rica (artículo 11), entre otros.

Por ello, es razonable considerar que los postulados y conceptos teóricos aportados por el TEDH, que son propios de un ordenamiento y una jurisdicción supranacionales, pueden constituir un referente útil para la justicia comparada a la hora de resolver esta

\footnotetext{
${ }^{29}$ HenRíQueZ, Sebastián, Ob. cit., p. 67.

${ }^{30}$ García MurCia, Joaquín, Rodríguez CARDo, Iván y Álvarez Alonso, Diego, Ob. cit., 2019, p. 205.

${ }^{31}$ Ídem, p. 206.
} 
clase de conflictos, considerando además que algunos ordenamientos jurídicos se caracterizan por una regulación muy elemental y no exhaustiva en materia de derechos y obligaciones del vínculo entablado entre el trabajador y el empleador, de lo cual el control por parte del empresario mediante medios tecnológicos, no es la excepción.

El punto especialmente álgido o de conflicto, resulta ser la definición del contenido esencial del derecho a la vida privada del trabajador, o en su caso, delimitar los contornos del derecho a la protección de datos personales, en aquellos sistemas que lo tienen consagrado como un derecho autónomo. En concreto, las dificultades se amplían en relación con la incorporación del derecho de información previa dentro del referido contenido esencial, lo cual sin lugar a dudas constituiría una medida tuitiva para los intereses de los trabajadores en aquellos casos en que se pretendan introducir tecnologías en el ámbito de la empresa con fines de vigilancia.

Los vaivenes pendulares de la jurisprudencia del TEDH son un reflejo de la dificultad apuntada, aunque demostrativos de la relatividad de los derechos fundamentales, cuando entran en conflicto con otros intereses, prerrogativas o derechos que ameritan una similar protección constitucional. En definitiva, tal como se ha señalado por parte de la doctrina científica, el contrato de trabajo no puede servir de fundamento para despojar transitoriamente al trabajador de sus derechos fundamentales, pero tampoco podrán estos ser invocados con la finalidad de tornar nulos los poderes empresariales ${ }^{32}$.

Sin perjuicio de dicho apunte, también cabe considerar que las matizaciones o modulaciones que pudieran introducirse a los derechos fundamentales de los trabajadores de la vida privada o protección de datos personales encuentran un cauce o pautas mínimas infranqueables. En efecto, por un lado, el denominado test Barbulescu será de especial importancia a la hora de la dilucidación de los conflictos de esta naturaleza; y, asimismo, por otro lado, existe conciencia en torno a la ratificación de que el control o vigilancia que pretenda introducir el empleador en el ámbito del trabajo, debe en principio excluir la posibilidad del monitoreo secreto de la prestación laboral. En efecto, la videovigilancia encubierta está generalmente y de principio prohibida, y sólo es admisible en casos excepcionales cuando exista una sospecha razonable de robo, no verificándose una "carta en blanco" a favor del empleador para practicar el monitoreo pretendido ${ }^{33}$.

\footnotetext{
${ }^{32}$ SALA FrANCO, Tomas, "El derecho a la intimidad personal y el control del trabajador", en AAVV, La jurisprudencia constitucional en materia laboral y social en el periodo 1999-2010, Libro Homenaje a María Emilia Casas, La Ley, 2015, p. 314.

${ }^{33}$ HENDRICKX, Frank, "Video surveillance at work: European Human Rights Court approves hidden cameras", Regulating for Globalization, entrada de Blog del 18.10.2019, Wolters Kluwer. Disponible en http://regulatingforglobalization.com/2019/10/18/video-surveillance-at-work-european-human-rights-
} 


\section{Bibliografía}

CABEZA, Jaime, "El necesario cambio en la jurisprudencia constitucional sobre videovigilancia y control de mensajería electrónica de los trabajadores a la vista de la doctrina del TEDH", Temas Laborales, No 141/2018, 2018.

CABEZA, Jaime, "La protección jurisdiccional de los derechos humanos y libertades fundamentales de los trabajadores ante el TEDH", Revista de Derecho Social, No 69 , Editorial Bomarzo, Albacete, 2015.

Chacartegui, Consuelo; "Videovigilancia en el lugar de trabajo y 'expectativa razonable de privacidad' según el Tribunal Europeo de Derechos Humanos. Comentario a la sentencia de 9 de enero de 2018 [caso López Ribalda contra España]", Revista de Derecho Social, № 83, Editorial Bomarzo, Albacete, 2018.

ECheVARRía De RADA, María Teresa, "Protección de datos y Videovigilancia en el ámbito laboral", Actualidad Civil, No 9, Wolters Kluwer, septiembre, 2019. Disponible en https://laleydigital-laleynext-es, LALEY 10667/2019 [consultado el día 12.06.2020].

ERMIDA URIARTE, Óscar, "Derechos humanos laborales en el derecho positivo uruguayo", en BARRETO GHIONE, Hugo, Investigación sobre la aplicación de los principios $y$ derechos fundamentales en el trabajo en Uruguay, Organización Internacional del Trabajo, Lima, 2006.

GALlardo, Rosa, "Un límite a los límites de la vida privada y de la correspondencia en los lugares de trabajo. Comentario a la sentencia del Tribunal Europeo de Derechos Humanos (Gran Sala) de 5 de setiembre de 2017 en el caso Barbulescu II c. Rumania”, Revista de Derecho Social, No 79, Editorial Bomarzo, Albacete, 2017.

García Murcia, Joaquín, Rodríguez CARdo, Iván y Álvarez Alonso, Diego, "Poderes empresariales y derechos del trabajador en el contexto de las nuevas tecnologías: aportaciones recientes de la legislación española”, Minerva: Revista de Estudos Laborais, Año IX, I de 4ª Serie, N² 2, 2019.

GoÑI, José Luis, "Los derechos fundamentales inespecíficos en la relación laboral individual: ¿necesidad de una reformulación?”, Los derechos fundamentales inespecíficos en la relación laboral y en materia de protección social, Ediciones Cinca, Madrid, 2014.

HENDRICKX, Frank, "Video surveillance at work: European Human Rights Court approves hidden cameras", Regulating for Globalization, entrada de Blog del 18.10.2019, Wolters Kluwer. Disponible en http://regulatingforglobalization.com/2019/10/18/video-surveillance-at-work-europeanhuman-rights-court-approves-hiddencameras/?doing_wp_cron=1592075692.3358778953552246093750.

court-approves-hidden-cameras/?doing_wp_cron $=1592075692.3358778953552246093750$ [consultado el día 13 de junio de 2020]. 
HENRÍQueZ, Sebastián, "Protección de datos, videovigilancia laboral y doctrina de la sentencia López Ribalda II: un peligroso camino hacia la degradación de la obligación de información", IUSLabor, nº 3, 2019.

Palomeque López, Manuel Carlos y Álvarez de la Rosa, Manuel, Derecho del Trabajo, Editorial Universitaria Ramón Areces, vigesimocuarta edición, Madrid.

Preciado Domènech, Carlos, "Comentario de urgencia a la STEDH de 5 de septiembre de 2017. Caso Barbulescu contra Rumanía [Gran Sala]. Recuperando la dignidad en el trabajo", Jurisdicción Social. Blog de la Comisión de lo Social de Juezas y Jueces para la Democracia, 5.09.2017. Disponible en https://bit.ly/2zeEMai.

Rojo TORRECILlA, Eduardo, "Medias verdades y fake news en el mundo jurídico. No cabe todo en la videovigilancia de una persona trabajadora. A propósito de la sentencia "López Ribalda" de la Gran Sala del TEDH de 17 de octubre de 2019 (y recordatorio de la sentencia de Sala de 9 de enero de 2018 y del caso Barbulescu II, sentencia de Gran Sala de 5 de septiembre de 2017)", El nuevo y cambiante mundo del trabajo. Una mirada abierta y crítica a las nuevas realidades laborales, entrada de Blog del 23.10.2019. Disponible en http://www.eduardorojotorrecilla.es/2019/10/mediasverdades-y-fake-news-en-el-mundo.html.

SALA FRANCO, Tomás, "El derecho a la intimidad personal y el control del trabajador", en AAVV, La jurisprudencia constitucional en materia laboral y social en el periodo 1999-2010, Libro Homenaje a María Emilia Casas, La Ley, 2015.

TALÉNS, Eduardo, "Vídeo-vigilancia y protección de datos en el ámbito laboral: una sucesión de desencuentros", Revista Internacional y Comparada de Relaciones Laborales y Derecho del Empleo, Volumen 6, N 3, ADAPT, julio-septiembre, 2018.

TERRADILlOS, Edurne, "El principio de proporcionalidad como referencia garantista de los derechos de los trabajadores en las últimas sentencias del TEDH dictadas en materia de ciberderechos: un contraste con la doctrina del Tribunal Constitucional Español", Revista de Derecho Social, No 80, Editorial Bomarzo, Albacete, 2017.

TORTUERO PlazA, José Luis, "La información relativa a la salud y el derecho a la intimidad en la doctrina del TC", La jurisprudencia constitucional en materia laboral y social en el período 1999-2010, Libro Homenaje a María Emilia Casas, La Ley, 2015. 